Selcuk Journal of Agriculture and Food Sciences

http://sjafs.selcuk.edu.tr/sjafs/index

Research Article
SJAFS

(2020) 34 (1), 99-106

e-ISSN: $2458-8377$

DOI:10.15316/SJAFS.2020.201

\title{
Fuzzy Knowledge-Based Model for Prediction of the Terminal Velocities of the Chickpea and Dry Bean Seeds
}

\author{
Serhat SOYLU ${ }^{1, *}$, Kazım ÇARMAN ${ }^{2}$, Ergün ÇITIL ${ }^{2}$ \\ ${ }^{1}$ Selcuk University, Akören Ali Rıza Ercan Vocatıonal School, Department of Electronic Technology, Konya, Turkey \\ ${ }^{2}$ Selcuk University, Faculty of Agriculture, Department of Agticulturel Mahineries and Tecnologies Engineering,
} Konya, Turkey

\begin{tabular}{l}
\hline ARTICLE INFO \\
\hline Article history: \\
Received date: 11.03 .2020 \\
Accepted date: 24.03 .2020 \\
\hline Edited by: \\
Osman ÖZBEK; Selçuk University, \\
Turkey \\
Reviewed by: \\
Alper TANER; Ondokuz Mayls Univer- \\
sity, Turkey \\
Mehmet HACIBEYOĞLU; Necmettin \\
Erbakan University, Turkey \\
\hline Keywords: \\
Seed \\
Terminal velocity \\
Physical properties \\
Fuzzy Expert System \\
Prediction
\end{tabular}

\begin{abstract}
Aerodynamic properties of solid materials have long been used to convey and separate seeds during harvest and postharvest operations. In this study, the terminal velocities of chickpea (Cicer arietinum L.) and dry bean (Phaseolus vulgaris L.) seeds as a function of seed mass and projected area were determined and also it was predicted by the fuzzy knowledge-based model. The results showed that the terminal velocity increased non linearly from 6.46 to $7.567 \mathrm{~m} \mathrm{~s}^{-1}$ for chickpea and from 5.224 to $6.463 \mathrm{~m} \mathrm{~s}^{-1}$ for dry bean with an increase in seed mass and projected area. In this paper, a sophisticated intelligent model, based on Mamdani approach fuzzy modeling principles, was developed to predict the terminal velocities of chickpea and dry bean seeds. The verification of the proposed model is achieved via various numerical error criteria. The relative error of predicted values was found to be less than the acceptable limits (10\%).
\end{abstract}

\section{Introduction}

Chickpea (Cicer arietinum L.) and dry bean (Phaseolus vulgaris L.) are a high protein (22-34\%) legume crop used primarily for direct human consumption. It is best adapted to the cooler temperate zones of the world, or the winter season in the Mediterranean climates. In Turkey, legume production has a total area of 8.8 million decars. Chick pea and dry bean are planted in $67 \%$ of this area. The total production of chickpeas and dry beans is about 850,000 tons that is about $70 \%$ of total legume production.

In handling and processing of agricultural products air or water are often used as a carrier transport for the separationofthedesirableproductfromthatofunwanted materials. Seed deparation can be accomplished by using pneumatic separators, screen cleaners, or gravity tables. Many commercial cleaners incorporate more than one of these cleaning methods. Thepneumatic separation and conveying systems have been used in agricultural machinery and food processing equipment

\footnotetext{
* Corresponding author email: serhatsoylu@selcuk.edu.tr
}

for many years. When an air stream is used for separating a product such as legume from its associated foreign materials, such as straw and chaff, knowledge of aerodynamic characteristics of all the particles involved is necessary. Therefore, the aerodynamic properties, such as terminal velocity, and drag coefficient, are needed to determine the proper air speed in either air conveyor or pneumatic separator. These parameters are affected by the density, shape, size, and moisture content of produce (Mohsenin, 1978; Omobuwajo et al., 1999; Gupta, et al., 2007)).

Several investigators determined the terminal velocity of various seeds such as African bread fruit seeds by Omobuwajo et al. (1999), millet grain by Baryeh (2002), pine nuts by Ozguven and Vursavus (2005), lentil seeds by Çarman (1996), makhana by Jha and Kachru(2007)and pistachio nut by Razavi et al. (2007).Terminal velocities were measured for both tef grain and straw. Terminal velocity increased linearly from 3.08 to $3.96 \mathrm{~ms}^{-1}$ with increase in moisture content from $6.50 \%$ to $30.21 \%$ w.b. by Zewdu (2007). Kural (1995)found that the effect on terminal velocity of the projection area, mass and sphericity of agricultural 
producesuch as wheat, barley, lentil and dry bean,were significant.

Fuzzy logic, which was first introduced by Zadeh (1965), is a self-learning technique that provides a mathematical tool to convert linguistic evaluation variables based on expert knowledge into an automatic evaluation strategy. Fuzzy set theory has been applied to a wide range of applications, such as process control, management, economic decision-making, operations research, event classification and image processing. Farzaneh et al., (2017) used a fuzzy system to predict physical properties of the fava bean seeds including geometric values as such length; width; thickness; arithmetic and geometric mean diameter; sphericity index surface and the area of the image. Yang et al. (2005) showed the feasibility of image processing and fuzzy logic control in the development of a precision farming herbicide application system. Çarman (2008) used a fuzzy system to predict soil compaction under pneumatic tires.

Table 1

Some physical properties of the chick pea and dry bean seeds

\begin{tabular}{lccc}
\hline & & Chickpea & Dry bean \\
\hline \multirow{2}{*}{ Seed mass $(\mathrm{g})$} & Max & 0.550 & 0.580 \\
& Mean & 0.427 & 0.436 \\
& Min & 0.240 & 0.290 \\
\hline \multirow{2}{*}{ Projected area $\left(\mathrm{cm}^{2}\right)$} & Max & 0.893 & 1.089 \\
& Mean & 0.656 & 0.884 \\
\hline \multirow{2}{*}{ Sphericity index $(\%)$} & Min & 0.497 & 0.711 \\
& Max & 91.50 & 69.70 \\
& Mean & 85.41 & 62.73 \\
\hline
\end{tabular}

The seed shapes were determined in terms of their sphericity and roundness indices as well as the aspect ratio (Mohsenin, 1978) using randomly selected seeds. The volume of a solid is equal to the volume of a triaxial ellipsoid with intercepts a, b and c; the sphericity index (Sp) was therefore defined as;

$S_{p}=\frac{(a b c)^{1 / 3}}{a} \times 100$

Each seedmasswas weighed with a digital electronic balance having an accuracy of $0.001 \mathrm{~g}$.

The projected area was determined from the pictures of seeds which were taken by a digital camera (13 Mpixels camera), in comparison with the reference area to the sample area by using the Fiji imagej computer program (Isık and İzli, 2007).

To determine the $V_{t}$ value of chick pea and dry bean seeds, a vertical wind tunnel was designed based on recommendations by Nalbandi et al.(2010), Shahbazi, et al.(2014) and Afonso et al. (2007). A centrifugal fan powered by $0.37 \mathrm{~kW}$ motor was used in the inlet of the wind tunnel to supply air flow. The airflow rate of the fan was controlled at the inlet and adjusted by changing the velocity of the electric motor through an inverter set. To measure the $V_{t}$ of the seeds, a uniform
The objective of this study was to investigate the terminal velocities as a function of mass and projected area of chickpea and dry bean seeds. Inaddition, in this study was the construction of fuzzy knowledge-based models for the prediction of the terminal velocities based on the Mamdani approach. The mathematical and statistical methods were used to validate the fuzzy models.

\section{Materials and Methods}

The chickpea and dry bean seeds used for the present study were obtained from a farmer field in the Çumra district of Konya that were cultivated in 2019 cultivation season. After attaining optimum maturity, samples of the seeds were harvested by hand and cleaned in an air screen cleaner. The harvest moisture content of chick pea and dry bean seeds was $16 \%$ and $26 \%$ (w.b.). Thirty randomly chosen seeds were measured and the mean valued determined in experiments. Some physical properties of the chick pea and dry bean seeds were given in Table 1. velocity field was required in the cross section of the tunnel, where seeds were suspended. For this purpose, two straightener sections were set up which consisted of one layer of fine wire mesh screen located above the honey comb. The final section of the wind tunnel consisted of a plexiglass region where the $V_{t}$ of seed was measured. To determine the terminal velocity, each seed was placed in the centre of the crosssection of the wind tunnel on the screen. The air flow was then increased until the seed flotation point. At this moment, when the rotational movement of the seed was lowest, the air velocity was measured using a vane anemometer having at least $0.01 \mathrm{~m} \mathrm{~s}^{-1}$ accuracy. The $\mathrm{V}_{\mathrm{t}}$ of each seed was measured three times. For each condition the $V_{t}$ was calculated as the average of the velocity values obtained at the centre of the test section.

For implementation of fuzzy set theory into the models, the fuzzy logic toolbox from MATLAB R2016a was used. For prediction of terminal velocity by using fuzzy expert system (FES), seed mass and projection area were used as input parameters and terminal velocity was used as output. For fuzzification of these factors the linguistic variables low (L), middle (M) and high $(\mathrm{H})$. In this research, a Mamdani maxmin inference for inference mechanism and the center 
of gravity (Centroid) defuzzifier formula method for defuzzification were used because these operators assure a linear interpolation of the output between the rules. Total of 9 rules were formed. Rules can be interpreted as follows.

Rule 1: If projection area $=\mathrm{L}$ and mass $=\mathrm{L}$ then terminal velocity $=\mathrm{L}$

Rule 2: If projection area $=\mathrm{L}$ and mass $=\mathrm{M}$ then terminal velocity $=\mathrm{M}$

Rule 3: If projection area $=\mathrm{L}$ and mass $=\mathrm{H}$ then terminal velocity $=\mathrm{M}$

Rule 4: If projection area $=\mathrm{M}$ and mass $=\mathrm{L}$ then terminal velocity $=\mathrm{M}$

Rule 5: If projection area $=\mathrm{M}$ and mass $=\mathrm{M}$ then terminal velocity $=\mathrm{M}$

Rule 6: If projection area $=\mathrm{M}$ and mass $=\mathrm{H}$ then terminal velocity $=\mathrm{M}$

Rule 7: If projection area $=\mathrm{H}$ and mass $=\mathrm{L}$ then terminal velocity $=\mathrm{M}$

Rule 8: If projection area $=\mathrm{H}$ and mass $=\mathrm{M}$ then terminal velocity $=\mathrm{M}$

Rule 9: If projection area $=\mathrm{H}$ and mass $=\mathrm{H}$ then terminal velocity $=\mathrm{H}$

Fuzzifications of the used factors were made by aid follows functions. These formulas are determined by using measurement values.

For chickpea;

projection area $\left(i_{1}\right)=\left\{\begin{array}{c}i_{1} ; 0.3 \leq i_{1} \leq 1.0 \\ 0 ; \text { otherwise }\end{array}\right\}$

$\operatorname{mass}\left(i_{2}\right)=\left\{\begin{array}{c}i_{2} ; 0.1 \leq i_{2} \leq 0.7 \\ 0 ; \text { otherwise }\end{array}\right\}$

terminal velocity $\left(o_{1}\right)=\left\{\begin{array}{c}o_{1} ; 4.5 \leq o_{1} \leq 9.5 \\ 0 ; \text { otherwise }\end{array}\right\}$

For dry bean;

projection area $\left(i_{1}\right)=\left\{\begin{array}{c}i_{1} ; 0.3 \leq i_{1} \leq 1.2 \\ 0 ; \text { otherwise }\end{array}\right\}$

$\operatorname{mass}\left(i_{2}\right)=\left\{\begin{array}{c}i_{2} ; 0.1 \leq i_{2} \leq 0.7 \\ 0 ; \text { otherwise }\end{array}\right\}$

terminal velocity $\left(o_{1}\right)=\left\{\begin{array}{c}o_{1} ; 4.5 \leq o_{1} \leq 7.5 \\ 0 ; \text { otherwise }\end{array}\right\}$

The memberships of the used factors were obtained from above the formulas and shown in the Figures. 1-6. These membership functions helped in converting numeric variables into linguistic terms. For example, the linguistic expressions and membership functions of terminal velocity for dry bean obtained from the developed rules and above the formula were given as following.

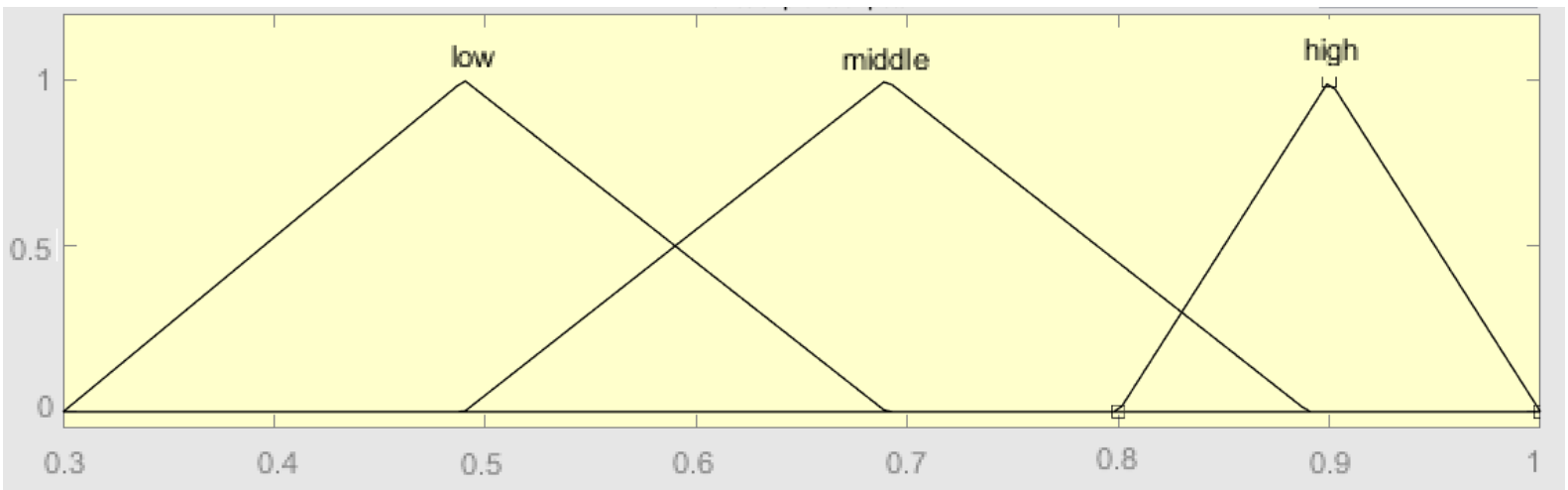

Figure 1

The membership function of projection area (input1) for chickpea.

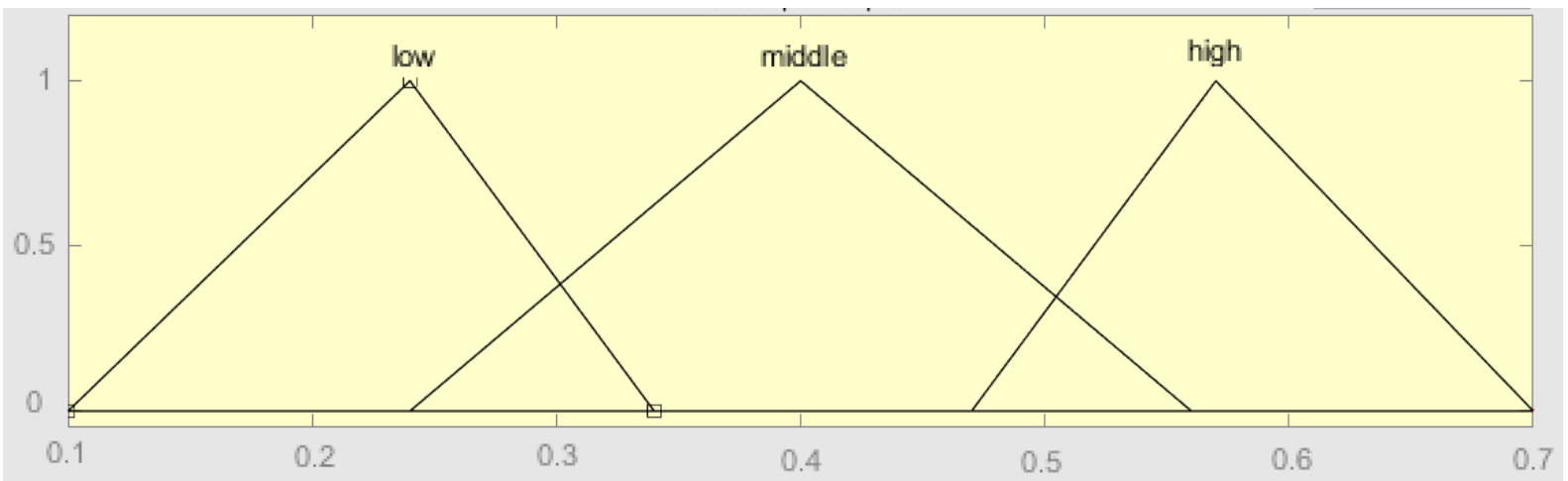

Figure 2

The membership function of mass (input2) for chickpea. 
Soylu et. al / Selcuk J Agr Food Sci, (2020) 34 (1), 99-106

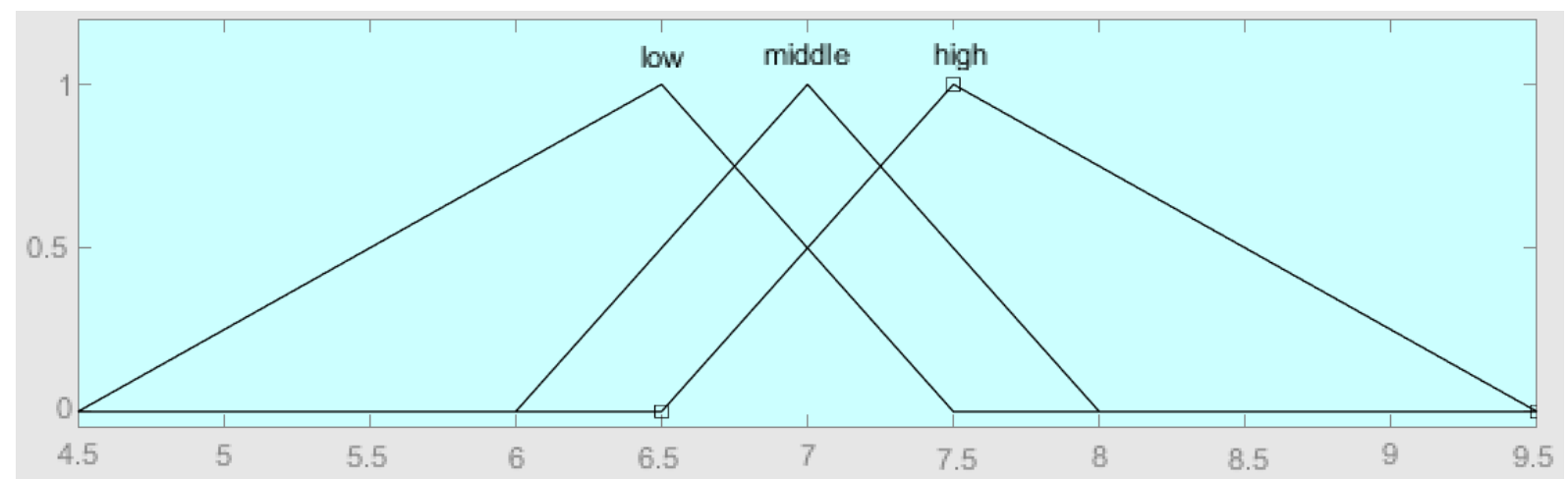

Figure 3

The membership function of terminal velocity (output) for chickpea.

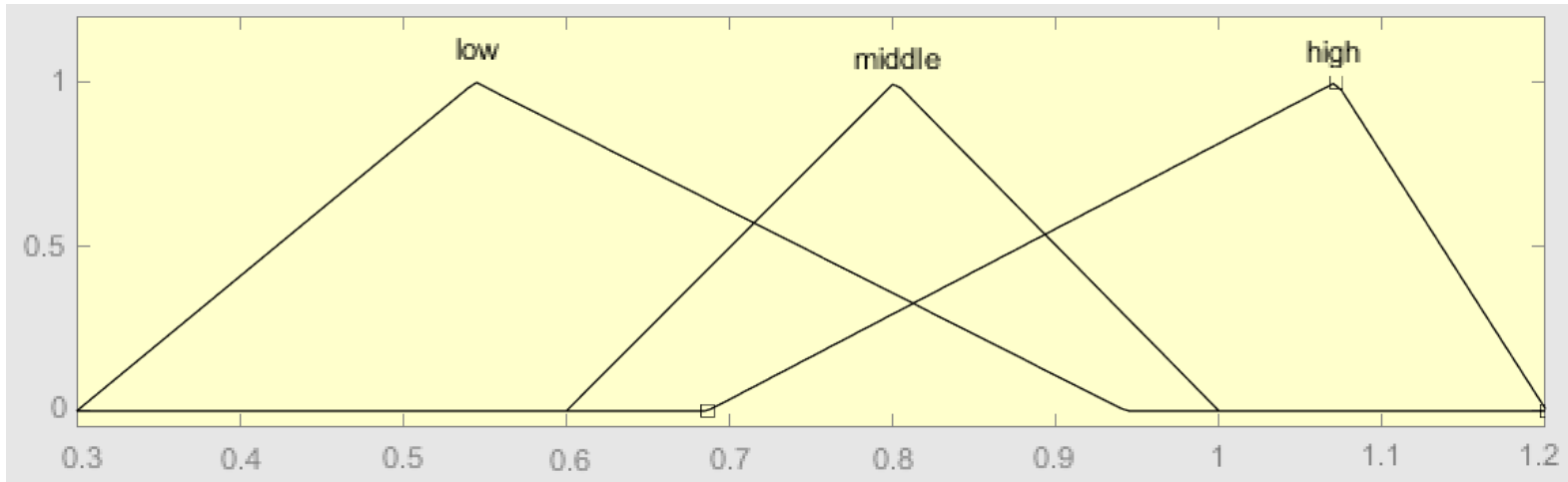

Figure 4

The membership function of projection area (input1) for dry bean.

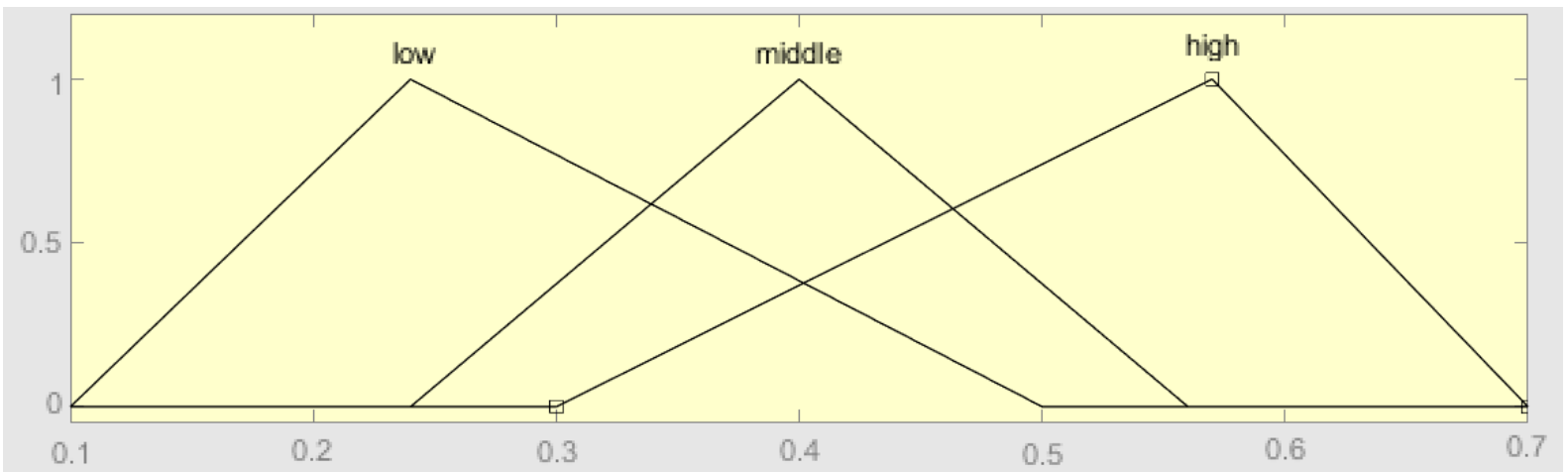

Figure 5

The membership function of mass (input2) for dry bean.

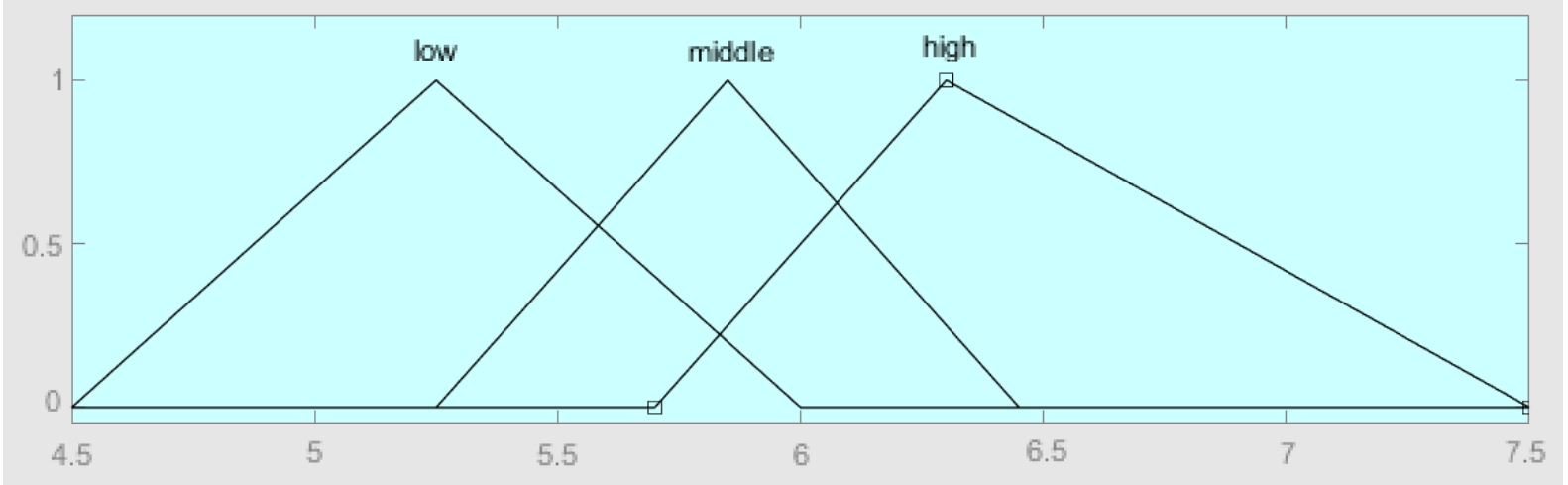

Figure 6

The membership function of terminal velocity (output) for dry bean. 


$$
\begin{gathered}
\mu_{\text {low }}\left(i_{1}\right)=\left\{\begin{array}{c}
\frac{i_{1}-0.3}{0.2443} ; 0.3 \leq i_{1} \leq 0.5443 \\
\frac{0.9429-i_{1}}{0.3986} ; 0.5443 \leq i_{1} \leq 0.9429 \\
0 ; i_{1}>0.9429
\end{array}\right\} \\
\mu_{\text {middle }}\left(i_{1}\right)=\left\{\begin{array}{c}
0 ; i_{1}<0.6 \\
\frac{i_{1}-0.6}{0.2014} ; 0.6 \leq i_{1} \leq 0.8014 \\
\frac{1.0-i_{1}}{0.1986} ; 0.8014 \leq i_{1} \leq 1.0 \\
0 ; i_{1}>1.0
\end{array}\right\} \\
0 ; i_{1}<0.6857 \\
\mu_{\text {high }}\left(i_{1}\right)=\left\{\begin{array}{c}
\frac{i_{1}-0.6857}{0.3853} ; 0.6857 \leq i_{1} \leq 1.071 \\
\frac{1.2-i_{1}}{0.129} ; 1.071 \leq i_{1} \leq 1.2 \\
0 ; i_{1}>1.2
\end{array}\right\}
\end{gathered}
$$

In defuzzification stage, truth degrees $(\alpha)$ of the rules were determined for the each rule by aid of the min and then by taking max between working rules. For example, for dry bean; projection area $\left(i_{1}\right)=$ $0.556 \mathrm{~cm}^{2}$ and $\operatorname{mass}\left(i_{2}\right)=0.21 \mathrm{~g}$, the rule 1 will be fired.

$\propto_{1}=\min$ (low projection area, low mass) $=$ min $(0.9706,0.7857)=0.7857$

From Mamdani max-min inference, the membership function of system will be found as $\max \left(\propto_{1}\right)=0.7857$. Then the crisp output can be calculated. In defuzzification, the method center of gravity was used as follows.

$O^{*}=\frac{\int O \cdot \mu_{(o)} d O}{\int \mu_{(o)} d O}$

where $O^{*}$ is the crisp value of output, $\mathrm{O}$ is the fuzzificated value and $\mu_{(o)}$ is the membership degree of fuzzificated value.

The predictive ability of the developed fuzzy logic system was examined according to the mathematical and statistical methods. In order to determine the performances of the results, $\varepsilon, D$ and $\mathrm{R}^{2}$ values that are considered to be the principal accuracy measures and that are based on the concept of the mean error and are commonly used were calculated using the following equations (Mikailsoy et al., 2018):

$$
\begin{aligned}
& R^{2}=1-\left(\sum_{i=1}^{n}\left(\tilde{y}_{i}-y_{i}\right)^{2}\right) /\left(\sum_{i=1}^{n}\left(\tilde{y}_{i}\right)^{2}\right) \\
& D=1-\sum_{i=1}^{n}\left(y_{i}-\tilde{y}_{i}\right)^{2} / \sum_{i=1}^{n}\left[\left|y_{i}-\bar{y}\right|+\left|\tilde{y}_{i}-\bar{y}\right|\right]^{2} \\
& \varepsilon=\frac{100}{n} \sum_{i=1}^{n} \frac{y_{i}-\tilde{y}_{i}}{y_{i}}
\end{aligned}
$$

Where; $R^{2}$ is the coefficient of determination, $\mathrm{D}$ is the agreement index, $\varepsilon$ is the relative error of the system, $\mathrm{n}$ is the number of data, $y_{i}$, is the measured ue, $\tilde{y}_{i}$, is the predicted value, and $\bar{y}$ is the mean value. The index $\mathrm{D}$ ranges from 0 to 1 , where the value 1 means a perfect accuracy of the predicted data, and the value 0 means that there is no accuracy.

\section{Results and Discussion}

The values of terminal velocity were found from 6.463-7.567 $\mathrm{m} \mathrm{s}^{-1}$ for chickpea seeds and from 5.224$6.463 \mathrm{~m} \mathrm{~s}^{-1}$ for dry bean seeds. According to the test results, the greater seed mass and projected area tests showed higher values of terminal velocity. The greatest terminal velocity obtained at seed mass of $0.55 \mathrm{~g}$ and projected area of $0.776 \mathrm{~cm}^{2}$ for chickpea and at seed mass of $0.54 \mathrm{~g}$ and projected area of $1.089 \mathrm{~cm}^{2}$ for dry bean. Kural (1995) reported that variation in physical properties of seeds such as mass, sphericity index and projected area, influenced terminal velocity significantly. The similar results was also found among seeds: lentil by Shahbazi et al., (2015), millets by Baryeh (2002), pistachio by Kashaninejad et al., (2006).

Depending on the seed mass and projection areas of chickpea and dry bean seeds, the change in terminal velocities were given in Figures 7 and 8. The correlation coefficient of the non linearly relationship between dependent variable with seed mass and projection area was found to be quite high. The values of terminal velocity of chickpea and dry bean seeds increased with increasing of seed mass and projected area. For chickpea and dry bean, approximately, an increase of $50 \%$ in seed projected area resulted in an terminal velocity increase of $17 \%$. Approximately, a mass increase of 58 $\%$ at chickpea seed and of $87 \%$ at dry bean seed caused a $15 \%$ and $24 \%$ increase of terminal velocity, respectively. Shahbazi et al., (2015) found that the terminal velocity occurred an increase of $32 \%$ with increasing projection area from 32.94 to $37.22 \mathrm{~mm}^{2}$ for lentil seeds. 


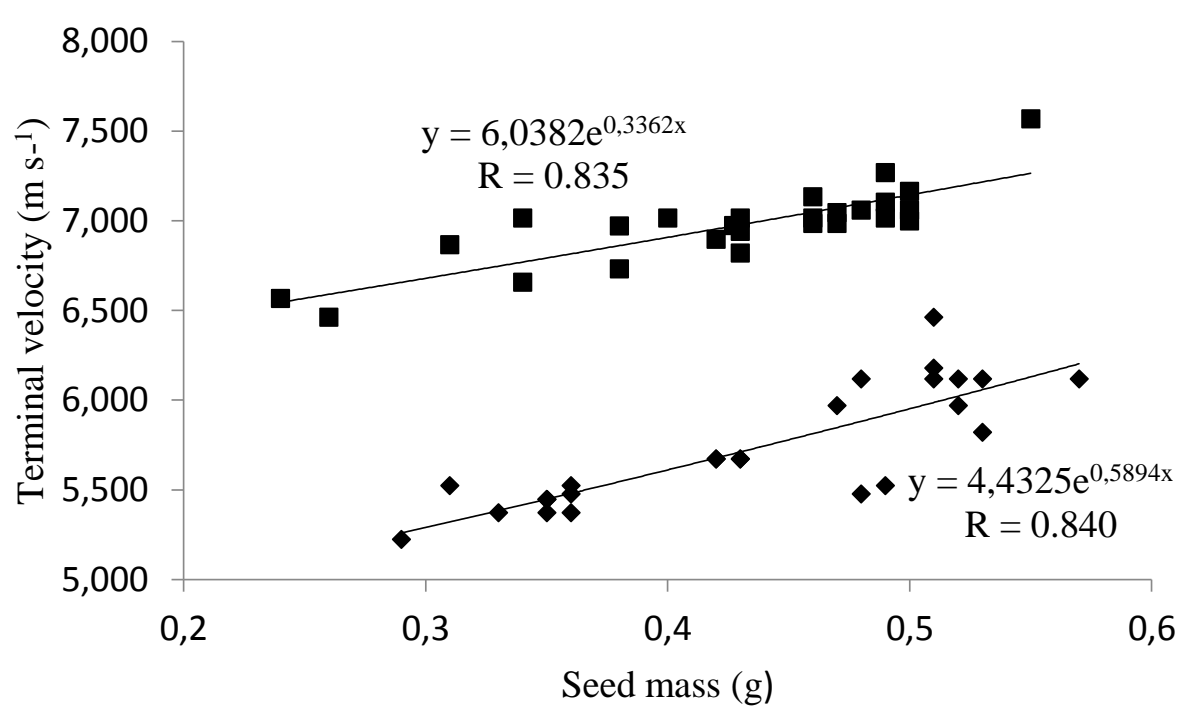

Figure 7

The effect on terminal velocity of seed mass for chickpea ( $\bullet$ ) and dry bean ( $\bullet$

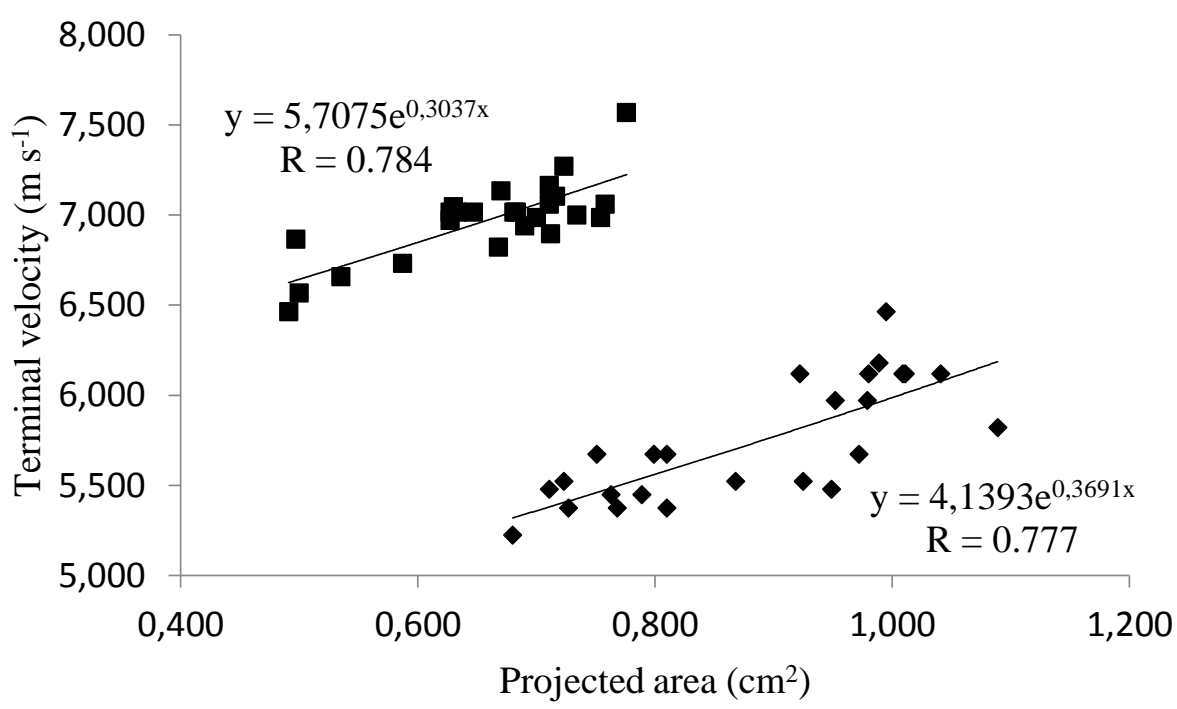

Figure 8

The effect on terminal velocity of projected area for chickpea ( - ) and dry bean ( $\bullet$

The results of the developed FES were compared with the experimental results. The mean of measured and predicted values were 5.738 and $6.032 \mathrm{~m} \mathrm{~s}^{-1}$ for dry bean, 6.974 and $7.017 \mathrm{~m} \mathrm{~s}^{-1}$ for chickpea respectively. The correlations between measured and predicted values of terminal velocity for chickpea and dry bean seeds were given in Figs. 9 and 10. The relationships were significant for all parameters. The correlation coefficients of relationships were found 0.809 for chickpea and 0.826 for dry bean. Farzaneh et al., (2017) studied with fuzzy logic system to predict an extensive range of physical properties of fava beans in the selected moisture contents of the input seeds (9.3$31.3 \%)$. The high correlation coefficient value $(0.999)$ between experimental and predicted values by fuzzy logic was found. Electronic maps of tree features such as tree type, age, yield, visual appearance and fruit length were created by fuzzy expert system for managing the groves. The average evaluation results for all five groves obtained from the FES showed $87 \%$ general conformity with the results from the human expert (Mazloumzadeh et al., 2010).

In the FES model, for dry bean, the coefficient of determination $\left(\mathrm{R}^{2}\right)$ was found to be 0.996 and the agreement index (D) value, which was the highest, was found to be 0.772 ; for chickpea, the $\mathrm{R}^{2}$ value was found to be 0.997 and the $\mathrm{D}$ value was found to be 0.729 . The mean relative error of measured and predicted values were $4.029 \%$ for chickpea and $5.611 \%$ for dry bean. For chickpea and dry bean seeds, the relative error of predicted value was found to be less than the acceptable limits (10\%) (Çarman and Taner, 2012). Roy et al., (2019) have developed a fuzzy prediction model of 
almond oil extraction. As a input parameters, pressure, temperature, heating time and moisture content were used, and the oil yield was output parameter. The coef- ficient of determination $\left(\mathrm{R}^{2}\right)$ and the mean relative error of predicted values was found as a 0.982 and 7.63 $\%$, respectively.

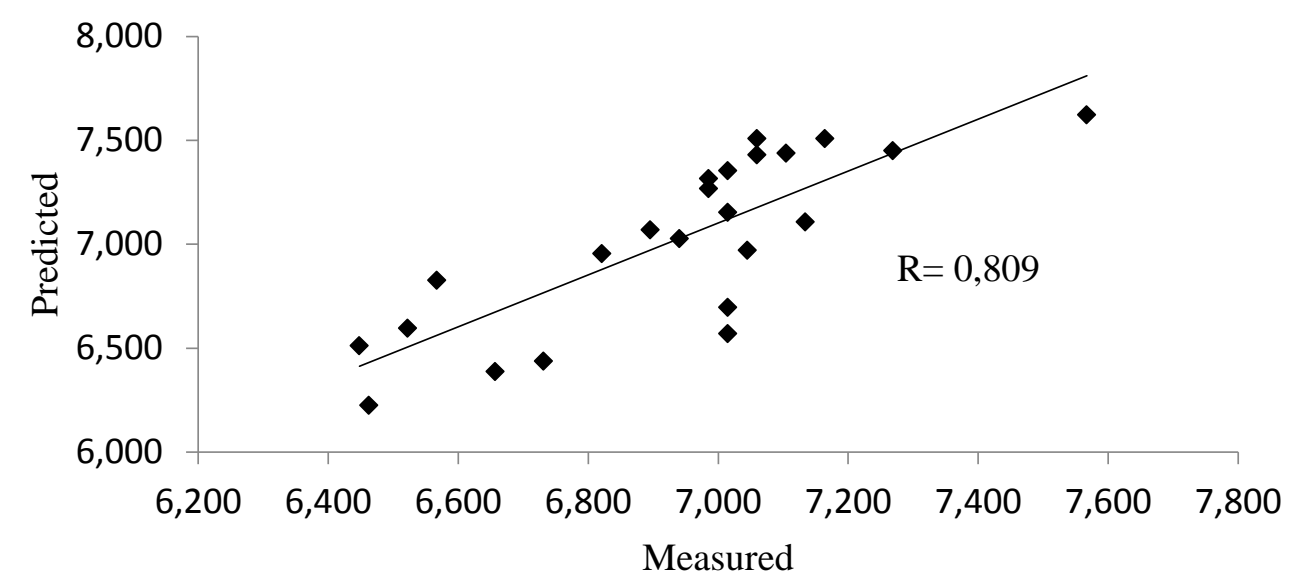

Figure 9

Correlation between measured and predicted values of terminal velocity for chickpea.

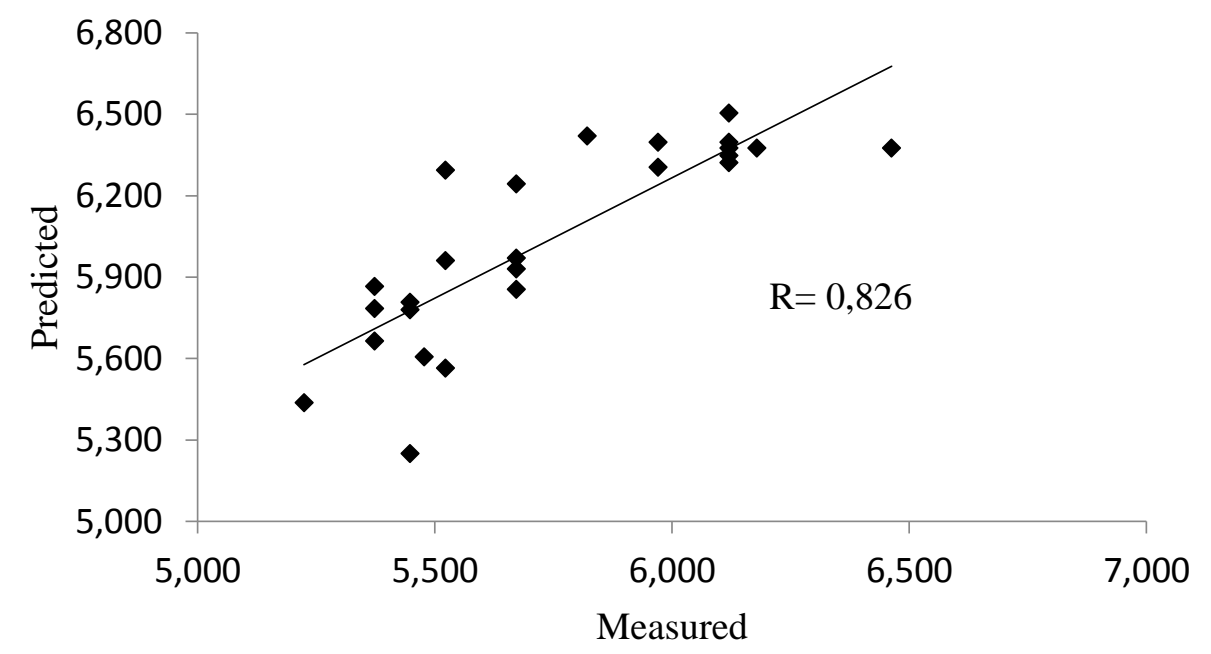

Figure 10

Correlation between measured and predicted values of terminal velocity for dry bean.

\section{Conclusion}

Maximum terminal velocity of chickpea and dry bean seeds to determine the proper air speed for conveying can be considered to be about $7.567 \mathrm{~m} / \mathrm{s}$ and $6.463 \mathrm{~m} \mathrm{~s}^{-1}$, respectively. Values higher than these numbers will lead to braking and wasting of seeds and less than that probably would not give results in separating of the seeds from each other or foreign material.

Prediction of terminal velocities of biological material is necessary for agricultural engineering applications. In comparison to other predictive modeling techniques (such as classical regression analysis), fuzzy models have the advantage of being simple (relations between input and output variables can be explained in a linguistic-based rule base) and robust (performance is not depending on training and new input variables and rules can be easily added). This study describes the developed fuzzy model consisting of 9 rules for the prediction of the terminal velocity of chickpea and dry bean seeds. In this paper, according to evaluation criterions of predicted performance of developed fuzzy knowledge-based model was found to be valid. The developed model can be used as a reference in studies related to determining the aerodynamic properties of biological material.This system can be developed further with increasing the knowledge rules from one side and with adding the neural network to the system from the other side.

\section{References}

Afonso JPC, Correa PC, Pinto FAC, Queiroz DM (2007). Aerodynamic properties of coffee cherries and beans. Biosystems Engineering, 98, 39-46. 
Baryeh EA (2002). Physical properties of millet. Journal of Food Engineering, 51(1): 39-46.

Çarman K, Taner A (2012). Prediction of tire tractive performance by using artificial neural networks. Mathematical and Computational Applications, 17 (3): 182-192.

Çarman K (1996). Some physical properties of lentil seeds. Journal of Agricultural Engineering Research, 63, 87-92.

Çarman K (2008). Prediction of Soil Compaction Under Pneumatic Tires a Using Fuzzy Logic Approach. Journal of Terramechanics, 45(4), 103-108.

Farzaneh V, Ghodsvalı A, Bakhshabadı H, Ganje M, Dolatabadı Z, Carvalho I (2017). Modelling of the selected physical properties of the fava bean with various moisture contents using fuzzy logic design. Journal of Food Process Engineering, 40, 1-9.

Gupta RK, Arora G, Sharma R (2007). Aerodynamic properties of sunflower seed (Helianthus annuus L.). Journal of Food Engineering, 79, 899-904.

Isık E, İzli N (2007). Moisture Dependent Physical and Mechanical Properties of Dent Corn (Zea mays var. indentata Sturt.) Seeds. American Journal of Food Technology, 2 (5), 342-353.

Jha SN, Kachru RP (2007). Physical and aerodynamic properties of makhana. The Journal of Food Process Engineering, 21, 301-316.

Kashaninejad M, Mortazavi A, Safekordi A, Tabil LG (2006). Some physical properties of pistachio (Pistacia vera L.) nut and its kernel. Journal of Food Engineering, 72, 30-38.

Kural H (1995). Determining of terminal velocities of some crops in free fall. Selçuk University, Graduate School of Natural and Applied Sciences of Agricultural Machinery, Master Thesis (In Turkish).

Mazloumzadeh SM, Shamsi H, Nezamabadi-pour H (2010). Fuzzy logic to classify date palm trees based on some physical properties related to precision agriculture. Precision Agriciculture, 11:258273. Mikailsoy F, Çarman K, Özbek O (2018). Non-linear modelling to describe the wind erosion rate in different tillage practices. Fresenius Environmental Bulletin, 27 (3), 1604-1612.

Mohsenin NN (1978). Physical Properties of Plant and Animal Materials. Gordon Breach Sci. Press, New York, USA.

Nalbandi H, Seiiedlou S, Ghassemzadeh HR (2010). Aerodynamic properties of Turgenia latifolia seeds and wheat kernels. International Agrophysics, 24, 57-61

Omobuwajo TO, Akande EA, Sanni LA (1999). Selected physical, mechanical and aerodynamic properties of African breadfruit (Treculia africana) seeds. Journal of Food Engineering 40, 241-244.

Razavi SMA, Rafe A, Akbari R (2007). Terminal velocity of pistachio nut and its kernel as affected by moisture content and variety. African Journal of Agricultural Research, 2(12), 663-666.

Roy K, Mukherjee A, Jana DK (2019). Prediction of maximum oil-yield from almond seed in a chemical industry: A novel type-2 fuzzy logic approach. South African Journal of Chemical Engineering, 29, 1-9.

Shahbazi F, Valizadeh S, Dowlatshah A (2014). Aerodynamic properties of Makhobeli, triticale and wheat seeds. International Agrophys, 28, 389-394

Shahbazi F, Valizadeh S, Dowlatshah A, Hassanzadeh E (2015). Aerodynamic properties of lentil seeds. International Agrophysics, 29, 391-396.

Vursavaş K, Özgüven F (2005). Fracture Resistance of Pine Nuts to Compressive Loading. Biosystems Engineering, 90(2): 185-191.

Yang CC, Prasher SO, Landry JA, Perret J, Ramaswamy HS (2005). Recognition of weeds with image processing and their use with fuzzy logic for precision farming. Canadian Agricultural Engineering, 42, 195-200.

Zadeh LA (1965). Fuzzy sets. Information and Control, 8, 338-353.

Zewdu AD (2007). Aerodynamic properties of tef grain and straw material. Biosystems Engineering, 98, $304-309$. 